\title{
Excellentieonderwijs: wat vinden selecteurs en werkgevers belangrijk?
}

Citation for published version (APA):

van Broekhoven, K., Huijts, T., Isendam, M., Jacobs, M., Kolster, R., Leest, B., Meng, C., Westerheijden, D., \& Wolbers, M. (2020). Excellentieonderwijs: wat vinden selecteurs en werkgevers belangrijk? ROA. ROA Fact Sheets No. 001 https://doi.org/10.26481/umarof.2020001

Document status and date:

Published: 06/04/2020

DOI:

10.26481/umarof.2020001

Document Version:

Publisher's PDF, also known as Version of record

\section{Please check the document version of this publication:}

- A submitted manuscript is the version of the article upon submission and before peer-review. There can be important differences between the submitted version and the official published version of record.

People interested in the research are advised to contact the author for the final version of the publication, or visit the DOI to the publisher's website.

- The final author version and the galley proof are versions of the publication after peer review.

- The final published version features the final layout of the paper including the volume, issue and page numbers.

Link to publication

\footnotetext{
General rights rights.

- You may freely distribute the URL identifying the publication in the public portal. please follow below link for the End User Agreement:

www.umlib.nl/taverne-license

Take down policy

If you believe that this document breaches copyright please contact us at:

repository@maastrichtuniversity.nl

providing details and we will investigate your claim.
}

Copyright and moral rights for the publications made accessible in the public portal are retained by the authors and/or other copyright owners and it is a condition of accessing publications that users recognise and abide by the legal requirements associated with these

- Users may download and print one copy of any publication from the public portal for the purpose of private study or research.

- You may not further distribute the material or use it for any profit-making activity or commercial gain

If the publication is distributed under the terms of Article $25 \mathrm{fa}$ of the Dutch Copyright Act, indicated by the "Taverne" license above, 


\section{Excellentieonderwijs: wat vinden selecteurs en werkgevers belangrijk?}

WAT VINDEN SELECTEURS BELANGRIJK?

TOP TOP 5 BELANGRIJKSTE KENMERKEN

\begin{tabular}{|lrr|}
\hline motivatie & & $64 \%$ \\
\hline denkvermogen & $58 \%$ \\
\hline doorzettingsvermogen & $52 \%$ \\
\hline maatschappelijke betrokkenheid & $34 \%$ \\
\hline creativiteit & $32 \%$ \\
\hline
\end{tabular}

DIT VERGROOT DE KANS OM GESELECTEERD TE WORDEN

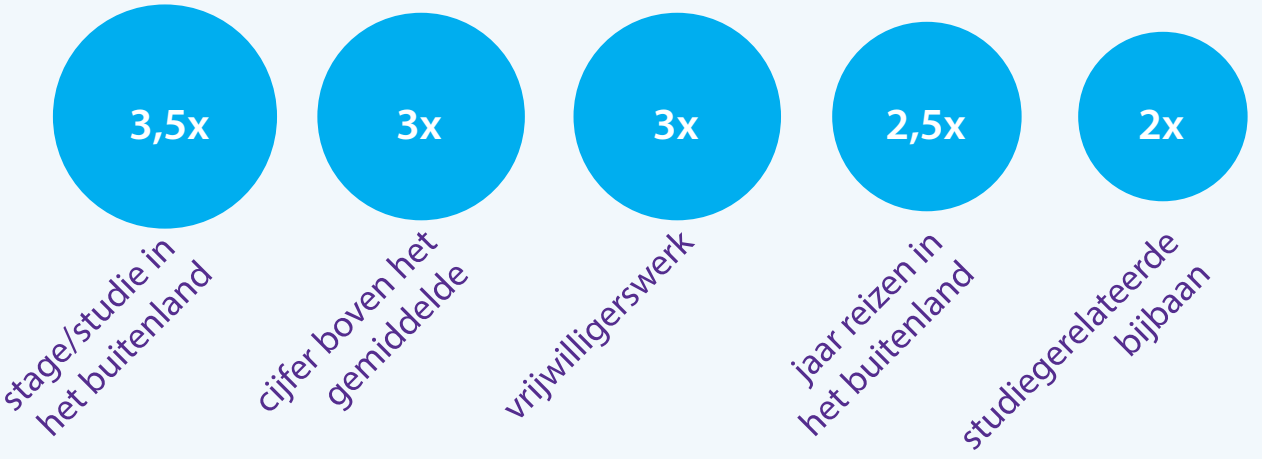

DIT ZIEN SELECTEURS NIET GRAAG

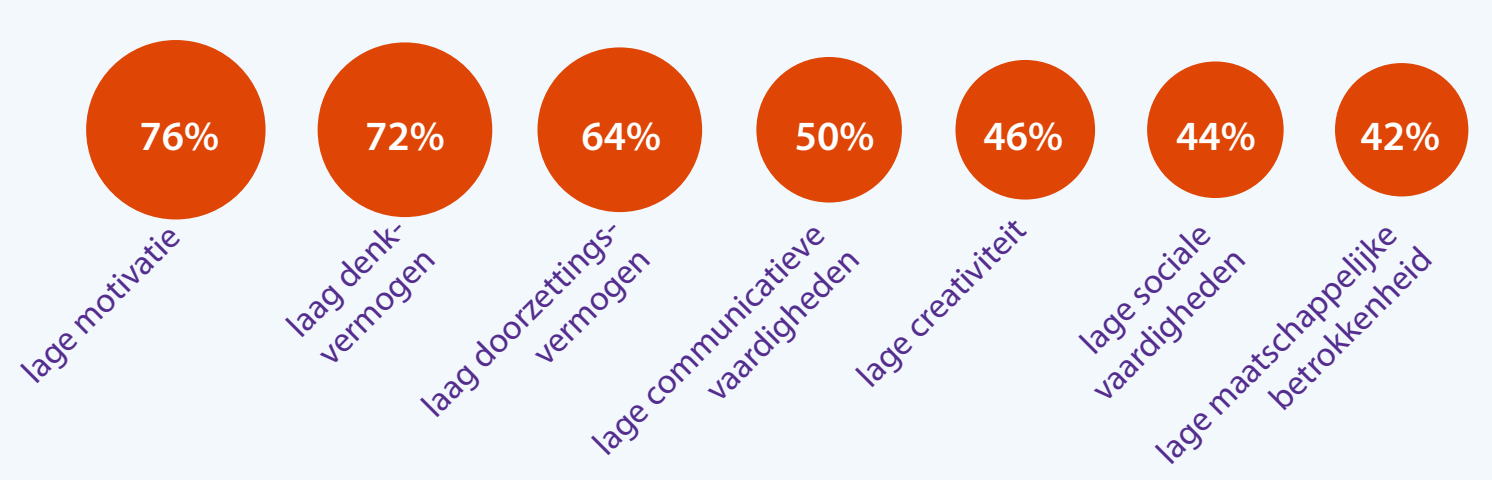

- Wat vinden selecteurs van

excellentieprogramma's de belangrijkste kenmerken waar studenten aan moeten voldoen?

ngschikten de kenmerke van minst naar meest belangrijk. Op basis hiervan stelden we een top 5 samen.

- Selecteurs zoeken verder niet alleen naar studenten met sterke cognitieve vaardigheden, maar ook naar doorzettingsvermogen, maatschappelijke betrokkenheid en creativiteit.

- Selecteurs kregen de vraag om te kiezen tussen 3 fictieve studenten voor de laatste plek in hun excellentieprogramma.

De potentiële kandidaten verschilden op buitenlandervaring, behaalde cijfers, bijbaan en vrijwilligerswerk.

De kans om aangenomen te worden voor een excellentieprogramma is bijvoorbeeld 2 keer zo groot voor studenten die een studiegerelateerde bijbaan hebben gedaan versus studenten die geen bijbaan hebben gehad.

We vroegen selecteurs ook wat ze niet aanvaardbaar vinden van studenten die in aanmerking willen komen voor ellentieprogramma's.

Wat vooral opvalt is dat studenten die tot de laagste $25 \%$ van de groep behoren op verschillende kenmerken vaak niet geschikt worden geacht voor excellentieprogramma's.

Studenten die met name lage motivatie (76\%) en laag denkvermogen $(72 \%)$ laten zien, worden als niet aanvaardbaar voor excellentieprogramma's beschouwd.
WAT VINDEN WERKGEVERS VAN EXCELLENTIEONDERWIJS?
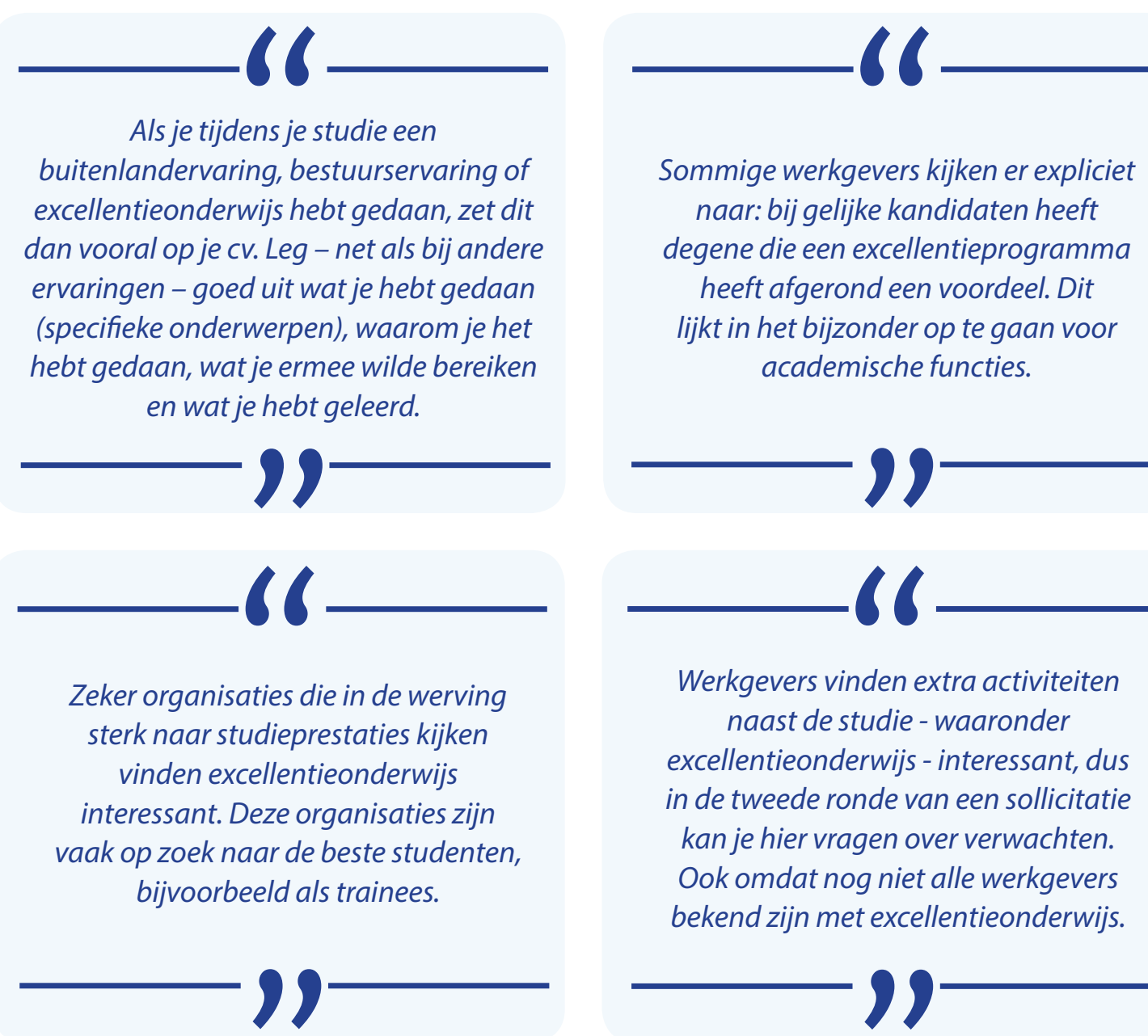

Sommige werkgevers kijken er expliciet naar: bij gelijke kandidaten heeft degene die een excellentieprogramma heeft afgerond een voordeel. Dit lijkt in het bijzonder op te gaan voor academische functies.

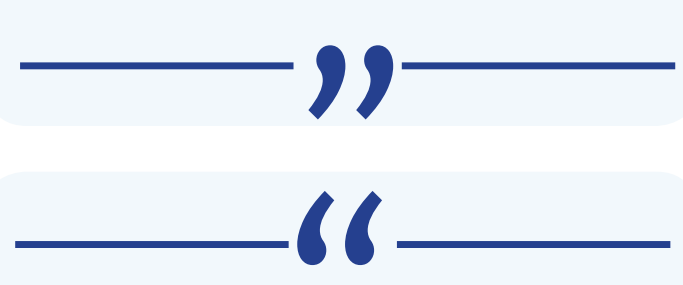

Werkgevers vinden extra activiteiten naast de studie - waaronder excellentieonderwijs - interessant, dus in de tweede ronde van een sollicitatie kan je hier vragen over verwachten. Ook omdat nog niet alle werkgevers bekend zijn met excellentieonderwijs. 9

OVER DIT ONDERZOEK

Dit onderzoek is onderdeel van het onderzoeksproject 'Excellentie in het hoger onderwijs: selectie, effectiviteit en uitstralingseffecten'. In deze factsheet hebben we de resultaten van de volgende onderdelen van dit onderzoek verwerkt:

8

Onderzoek onder selecteurs

so selecteurs van excellentieprogramma's hebben vragen beantwoord en vignetten ingevuld over welke student ze zouden aannemen voor hun

Werkgeversonderzoek

interviews met 20 HR-professionals over het voordeel van excellentieonderwijs en andere onderwijskeuzes in de werving van potentiële sollicitanten 